\title{
Failure of naloxone to reverse the cardiotoxocity of Distalgesic overdose
}

\author{
C. J. BARRACLOUGH \\ M.B., Ch.B.
}

\author{
R. A. LOWE \\ M.B. B.Chir.
}

Wharfedale General Hospital, Otley, West Yorkshire

\begin{abstract}
Summary
A case of severe poisoning with dextropropoxyphene and paracetamol (Distalgesic) in which the cardiotoxic effects of dextropropoxyphene were not reversed by naloxone is reported. A probable reason for this failure is suggested with reference to the differing pharmacological actions of dextropropoxyphene on cardiac conducting tissue and the central nervous system.
\end{abstract}

\section{Introduction}

It has been reported (Starkey and Lawson, 1978) that the cardiotoxicity of dextropropoxyphene overdose may be reversed in man by naloxone as are its recognized direct opiate effects. We report a case of acute poisoning with dextropropoxyphene where naloxone was ineffective in this respect, and refer to probable explanations for this.

\section{Case report}

An 18-year-old youth presented half an hour after taking approximately 50 of his mother's Distalgesic tablets (containing dextropropoxyphene $32.5 \mathrm{mg}$ and paracetamol $325 \mathrm{mg}$ per tablet) following a moderate amount of beer. He was noted to have brief fits in the ambulance and on arrival in hospital was having intermittent tonic spasms lasting about 30 seconds. Between these his respiration was normal and he remained brightly flushed throughout. His initial heart rate was regular at 60 per min, and his blood pressure was $100 / 60 \mathrm{mmHg}$, but the electrocardiogram (ECG) showed sinus rhythm with broad bizarre complexes and right axis devization (Fig. 1). He was given an immediate injection of $0.4 \mathrm{mg}$ naloxone intravenously at the time of blood sampling, but 10 mins after arrival he had further convulsions and was given $10 \mathrm{mg}$ of diazepam intravenously followed shortly afterwards by a further $0.4 \mathrm{mg}$ of naloxone. His heart rate decreased with increasingly bizarre complexes and full resuscitative measures were required including external cardiac massage for 20 min, intermittent positive pressure ventilation via endotracheal tube, $8.4 \%$ sodium bicarbonate and 1 $\mathrm{ml}$ of $1: 1000$ adrenaline. His heart rate re-established at approximately 80 beats per min but he remained completely unresponsive, hypotensive (BP $40 \mathrm{mmHg}$ systolic by palpation) and initially oliguric. Blood gases in the course of his cardiac arrest were markedly deranged ( $\mathrm{pH} 6.80, \mathrm{PCO}_{2} 9.7 \mathrm{kPa}(73$ $\mathrm{mmHg}), \mathrm{Po}_{2} 72 \cdot 3 \mathrm{kPa}(543 \mathrm{mmHg})$ on $100 \%$ oxygen standard bicarbonate $11 \mathrm{mmol} /$ litre) but were normal within $40 \mathrm{~min}\left(\mathrm{pH} 7.31, \mathrm{PCO}_{2} 5.1 \mathrm{kPa}\right.$ (38 $\mathrm{mmHg}), \mathrm{Po}_{2} 13.2 \mathrm{kPa}(99 \mathrm{mmHg})$ on air). At no point was hypoxia demonstrated and he was never cyanosed. Fluids were infused with close monitoring of the central venous pressure. He received further treatment with intravenous mannitol, dexamethasone and shortly afterwards gastric lavage, intravenous $\mathrm{N}$-acetyl cysteine and a third bolus of naloxone $(0.4 \mathrm{mg})$. He required mechanical ventilation for 12 $\mathrm{hr}$. It was $16 \mathrm{hr}$ before his gag reflex returned and 24 $\mathrm{hr}$ before he made purposeful responses to painful stimuli. Twelve hours after admission he developed haematuria, a haematoma of the right calf and altered blood was aspirated via the nasogastric tube. The maximum prothrombin ratio was $1 \cdot 5: 1$, but he had received Vitamin $K$ at the first signs of overt bleeding. The ECG was repeated at regular intervals as well as continuous ECG monitoring, but it was not until $24 \mathrm{hr}$ after admission that these returned to normal (Fig. 1). The maximum paracetamol level was $2900 \mu \mathrm{mol} /$ litre (435 mg/litre) at $5 \mathrm{hr}$ and poor serum clearance was shown by a level of 1870 $\mu \mathrm{mol} /$ litre $(280 \mathrm{mg} / \mathrm{litre})$ at $12 \mathrm{hr}$ and $20 \mu \mathrm{mol} / \mathrm{litre}$ ( $3 \mathrm{mg} / \mathrm{litre})$ at 2 days. Initial serum ethanol was 0.12 $\mathrm{mmol} /$ litre $(55 \mathrm{mg} / \mathrm{dl})$. Serum bilirubin was never more than minimally elevated. Serum transaminases were maximally elevated at $48 \mathrm{hr}$ (alanine transaminase 2175 u./litre, aspartate transaminase 850 u./litre) and it was nearly one month before these returned completely to normal. The patient was discharged after 2 weeks and his progress thereafter, apart from a large benign gastric ulcer, has been uncomplicated. 
(a)

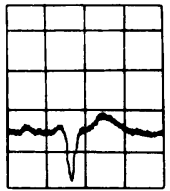

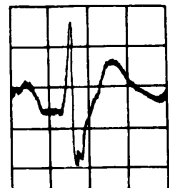

II

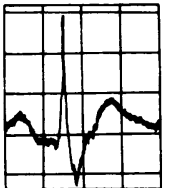

III

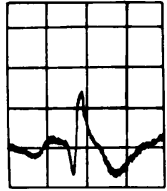

OVR

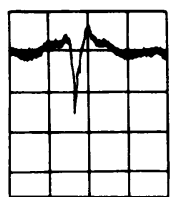

aVL

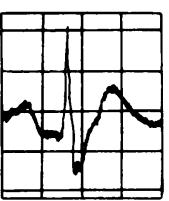

aVF

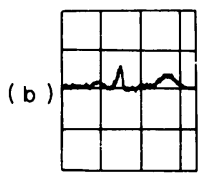

I

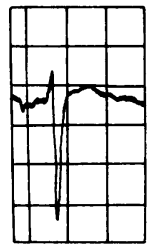

VI

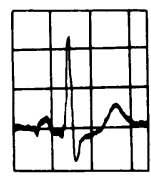

II

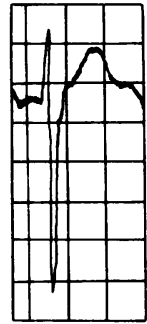

V2

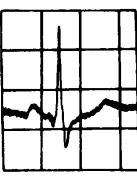

III

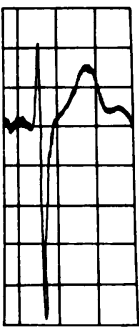

V 3

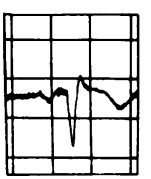

aVR

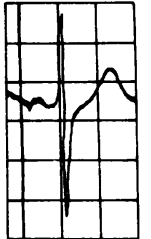

V 4

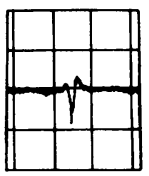

aVL

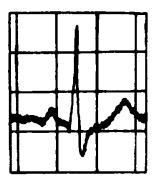

aVF

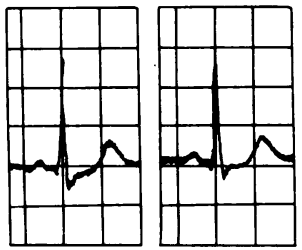

v 6

FIG. 1. (a) ECG on arrival in hospital and (b) $24 \mathrm{hr}$ after admission

\section{Discussion}

Distalgesic (a combination of paracetamol and dextropropoxyphene) is a commonly prescribed analgesic and frequently abused in self poisoning. Vomiting may be caused by either drug moiety and late effects of the paracetamol include liver failure. Clinical features of dextropropoxyphene overdosage include convulsions, pupillary constriction, coma and respiratory depression, which are generally accepted as due to opiate effects on the central nervous system and have been demonstrated to be reversed by naloxone clinically (Lovejoy, Mitchell and Goldman, 1974) as well as in animal studies. Less commonly, electrocardiographic changes have been reported including prolongation of the PR interval, widening of the QRS complex and non-specific $T$ wave and ST segment changes. These features are regarded as independent of any ischaemic changes secondary to respiratory depression (Sigurd and Jensen, 1971).

This case demonstrates several of the features described above with some response to naloxone with regard to central nervous system signs though the patient still required mechanical ventilation for a prolonged period. However, in spite of rapid administration of intravenous naloxone to a total of $1.2 \mathrm{mg}$, within $90 \mathrm{~min}$ of ingestion there was no improvement in the ECG changes. In animal studies it has been demonstrated that the cardiotoxic effects of dextropropoxyphene and its major metabolite norpropoxyphene are produced by a non-opiate action, are not reversed by naloxone and seem to reflect locab $\overrightarrow{0}$ anaesthetic-like activity of these drugs on cardiac o conducting tissue (Holland and Steinberg, 1979웅

Nickander, Smits and Steinberg, 1977).

We suggest that although naloxone is of proven value in the treatment of opiate effects of dextropropoxyphene, and clearly of value in overdose, the disturbances of cardiac rhythm are not affected. These should be treated with relevant supportive measures since they are temporary and potentially recoverable.

\section{Acknowledgment}

We thank Dr R. Seidelin for his permission to report this case.

\section{References}

Holland, D.R. \& Steinberg, M.I. (1979) Electrophysiologic properties of propoxyphene and norpropoxyphene in canine cardiac conducting tissues in vitro and in vivo. Toxicology and Applied Pharmacology, 47, 123.

LOVEJOY, F.H. JR., MitCHELl, A.A. \& GoldMAN, P. (1974) The management of propoxyphene poisoning. Journal of Pediatrics, $85,98$.

Nickander, R., Smits, S.E. \& Steinberg, M.I. (1977) Propoxyphene and norpropoxyphene pharmacologic and toxic effects in animals. Journal of Pharmacology and Experimental Therapeutics, $Q$ $200,245$.

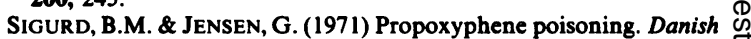
Medical Bulletin, 18, 166.

STARKEY, I.R. \& LAWSON, A.A.H. (1978) Acute poisoning with distalgesic. British Medical Journal, 2, 1468. 